\title{
The Virtual International Day of the Midwife: A Synchronous Open Online Conference for Continuing Professional Development and Learning for Midwives
}

\author{
Mary Sidebotham, Annette Dalsgaard, Deborah Davis, and \\ Sarah Stewart
}

\begin{abstract}
AIM: To examine the contribution of the Virtual International Day of the Midwife (VIDM) conference to midwives' continuing professional development (CPD).

BACKGROUND: Knowledge and understanding of CPD for midwives as synchronous online learning is limited. Studies of e-learning programs for CPD have underlined the need for interaction with others. The VIDM is a synchronous online 24-hour conference freely available for midwives designed to provide a unique CPD opportunity.

METHOD: An online survey with a mix of fixed-response, multiple-response, and open-ended freetext questions was available to participants for 1 month after the conference via the wiki page in 2012 and 2013.

FINDINGS: The survey was completed by 239 conference participants. Midwifery students and clinical midwives were the largest groups of attendees. The most common countries of residence were Australia, United Kingdom, and United States. Respondents believed that the conference contributed to their professional development by enabling professional growth, facilitating shared learning, and raising awareness of global issues.
\end{abstract}

CONCLUSION: Offering synchronous events is important to facilitate deeper learning for those engaging in online activities. As an annual synchronous 24-hour, open online conference, the VIDM has become a valuable CPD opportunity for midwives.

KEYWORDS: midwifery professional development; synchronous online conference; online learning; social media

\section{INTRODUCTION}

Midwives are autonomous health professionals who work in partnership with women and their families to facilitate a healthy pregnancy, labor, and postpartum period (International Confederation of Midwives [ICM], 2011a, 2013). To provide contemporary evidence-based care, it is essential that midwives become lifelong learners and engage in continuing education and professional development activities regularly to maintain their knowledge base and competence (ICM, 2011b).

Vygotsky's (1978) theory of the zone of proximal development suggests that learning takes place in a social context, with students learning from each other. Studies on continuing professional development (CPD) for midwives have highlighted that midwives do value the opportunity to interact with and share information and experiences with other like-minded professionals 
(Fahy \& Monaghan, 2005; Russell, 2010). Midwives, however, struggle to access face-to-face CPD education. Like other health professionals, they cite geographical distance, work commitments, lack of time, and financial constraints as the reasons that restrict them from attending face-to-face activities where this level of interaction is possible (Brekelmans, Poell, \& van Wijk, 2013; Katsikitis et al., 2013). Consequently, in response to the need to provide accessible, flexible, and affordable professional education opportunities for midwives and other health professionals, there has been a growth in the volume of asynchronous and synchronous educational material offered online (Carroll, Booth, Papaioannou, Sutton, \& Wong, 2009). The flexibility of online learning also supports the concept of informal lifelong learning, enabling midwives to choose where and what they learn, at a time that suits them, according to their personal, professional, and learning needs (Koper \& Tattershall, 2004). Although there is growing evidence to show the value and acceptability of educational material offered online, there is an increasing awareness of the need to provide an opportunity for learners to develop social presence and interact with fellow learners and facilitators in an online learning environment (Mayne \& Wu, 2011). The degree of social presence experienced by the learner can influence the quality and quantity of interaction and consequently affect the educational benefits gained (Beldarrain, 2006). Most educational resources offered online do provide an opportunity for asynchronous interaction with the facilitator and colearners through discussion boards, but Gould, Papadopoulos, and Kelly (2014) argue that asynchronous online learning designed for studying alone without interaction and support from others is limited in value. They argue that this model restricts the learner's opportunity to reflect on the material with his or her peers in real time, and therefore lessens the opportunity for deep learning.

Current trends in the field of education offered within an online environment indicate a shift in pedagogical perspectives and theoretical frameworks. There is now an increasing focus on student interaction and the development of learner-centered constructivist environments to enable varying levels of interaction (Beldarrain, 2006). This has become possible as a consequence of the emergence of new technologies and the versatility of social software enabling educational designers to develop programs that foster collaboration among learners and facilitators, thus creating a true learning community (Beldarrain, 2006).

The Virtual International Day of the Midwife (VIDM) is a 24-hour synchronous online conference that meets this need for real-time reflection and interaction. The "free-to-access" conference was created in 2009 in an attempt to combine the convenience of online learning but add the ability for midwives to interact in real time and come together in a unique educational event to celebrate world midwifery on May 5th annually. The conference presents a different topic and presenter each hour with an opportunity for interactive discussion throughout the 24-hour period.

The conference has four aims: to provide midwives with the opportunity to engage with the latest evidence-based information and research about practice, to give researchers the chance to disseminate their work, to increase midwives' digital literacy, and to supply a venue for midwives to network and interact in real time and thus learn from each other (Stewart, Sidebotham, \& Davis, 2012a, 2012b). Conference participants have the opportunity to introduce themselves within the chat facility and interact directly with the presenters and fellow participants over a period of time, thus establishing social presence and connection.

To evaluate the success of the conference in meeting the stated aims, an online questionnaire was developed and is administered following the conference on an annual basis. Earlier survey evaluation data identified that there is a growing interest in accessing online material for $\mathrm{CPD}$ and that an online conference using web conferencing technology associated with social media can reach an international midwifery audience (Stewart et al., 2012b; Vilain \& Stewart, 2012). Slowinski (2000), however, identified that before people can connect and collaborate within an e-based learning environment, they need to have the necessary technical expertise to enable them to gain maximum benefit. In the first 3 years of the conference in 2009-2011, participants reported access problems because of difficulties in using the web conferencing technology and a lack of engagement with the online learning space (Stewart et al., 2012b). Changes were made in 2012 to shift web conferencing technology from Elluminate to Adobe Connect, and improvements were made to materials and resources supporting participation and involvement of speakers, facilitators, and participants. These improvements included clearer instructions on the wiki, reaccessing the conference, and a new design of the conference room with an enlarged chatbox with better possibilities for the participants to communicate about the topic being presented. The promotion of the event was widened, and Facebook and Twitter were used more extensively to open up the event to midwives around the world. 
To assess the ongoing value of the event following these changes and thus provide valuable information to those wishing to organize similar events in the future, the e-based questionnaire was developed further in 2012 and 2013 to specifically identify what motivated midwives to attend, how accessible the conference was particularly around issues of using the technology, and whether the conference was meeting professional development needs. This article presents the analysis of the online questionnaire completed by VIDM participants in 2012 and 2013.

\section{METHODS}

The VIDM questionnaire was developed in 2010 using connectivism as a theoretical framework in relation to online learning (Siemens, 2004) to generate data to inform ongoing and future development of the conference. The original survey consisted of a mix of 18 questions with fixed response, multiple response, and open-ended free text (Stewart et al., 2012a, 2012b). An additional four questions were added to the original questionnaire in 2013 related to motivation to attend and professional development. These additional questions were developed and piloted within the VIDM organizing committee to ensure user comprehension and content applicability. The survey was administered using online survey technology and made available to the conference participants via an online link on the conference wiki (http://www.vidm.org). The conference participants were provided with information about the survey in a preamble, and consent was implied by participation in and completion of the survey. The participants were reminded of their rights to withdraw at any stage without giving reasons. The survey was available for 1 month after the event and reminders to complete the survey were sent via the Facebook and Twitter pages. In 2013, additional statistical data on attendance was collected within the web conferencing technology Adobe Connect to support survey data. The questionnaire was available in English language only.

\section{Analysis}

Quantitative data from fixed- and multiple-response questions were entered into an SPSS database, and simple descriptive statistics were used to summarize responses. The qualitative data were analyzed using a dynamic model of iterative thematic analysis to identify meaning within and across the data (Gibson \& Brown, 2009). To facilitate analysis, all free-text responses in the survey were transcribed into a word document. The word document was read, reread, and then independently coded by two members of the research team (MS, AD). They came together to collate the findings and identify the major themes emerging from the data. The major themes and issues were discussed with the remaining research team members $(\mathrm{DD}, \mathrm{SS})$ who were familiar with the data to achieve agreement. Where disagreement occurred, all researchers returned to the data to reexamine and recode until agreement could be achieved. Using more than one analyst enhanced the reliability of the coding with respect to agreeing major themes and issues (Schneider, Whitehead, LoBiondoWood, \& Haber, 2013). NVivo software was used to sort and store the data. Quotes from the qualitative data are presented in italics.

\section{Data Handling}

All survey data were kept in a password-protected computer file to which only the research team had access.

\section{Ethical Issues}

Ethical approval was provided by the University of Canberra and Griffith University, Australia and Otago Polytechnic, New Zealand.

\section{FINDINGS}

It is impossible to determine the actual response rate to the survey because of the nature of the event with participants logging on and off throughout the 24-hour period. Several people accessed the event through college or university where it was streamed to groups of people, thus limiting access to the survey on an individual level at the time. The online survey was completed in part or completely by 239 respondents (103 in 2012 and 136 in 2013).

The statistical data from the web conferencing technology in 2013 showed that during the 24 sessions, the average number of participants per session was 122 and the highest number of participants in 1 session was 164. The data also indicated that some of the participants used mobile devices such as tablets or smartphones to participate in the conference. 


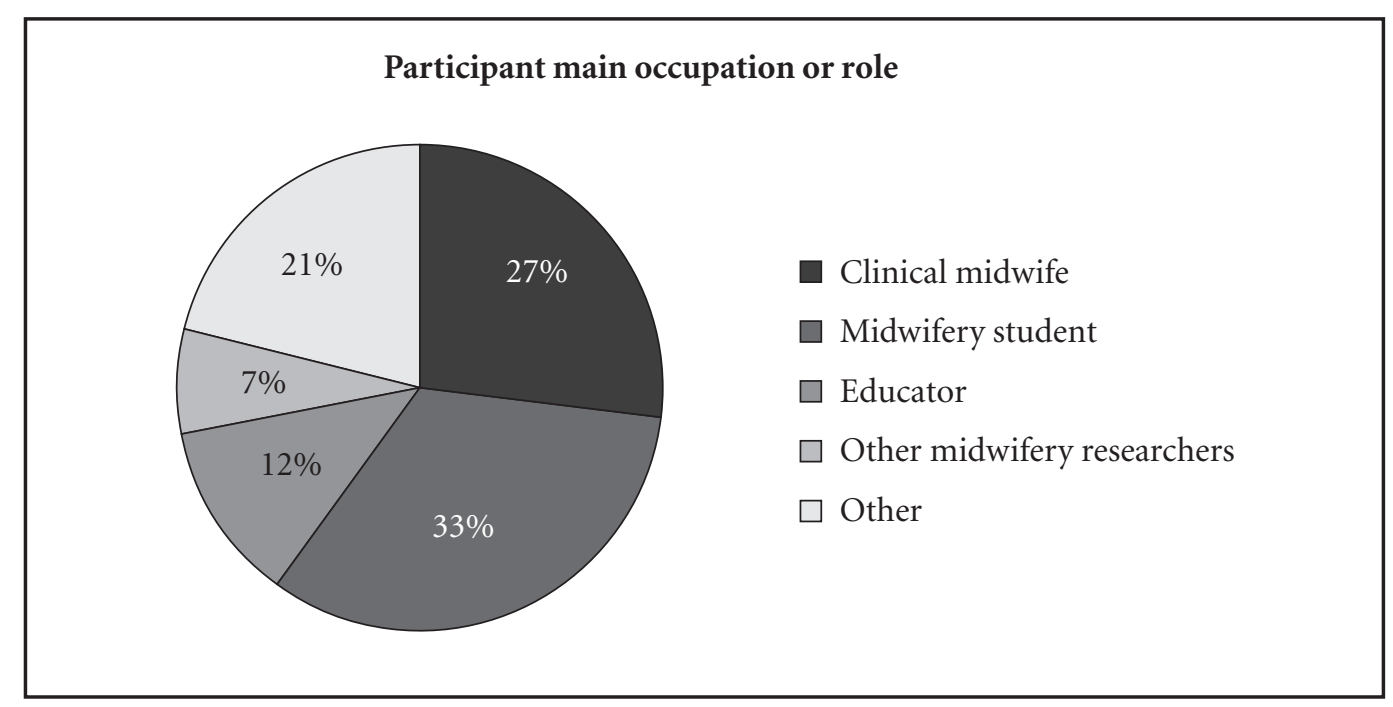

FIGURE 1 Main occupation or role.

\section{Participants}

Most survey respondents in 2012/2013 were midwifery students followed closely by midwives in clinical practice. Other categories represented included midwifery researchers, educators, and other health care professionals (see Figure 1).

The conference appealed to people of all ages with the largest number of attendees (in line with previous years' evaluation) being within the 30-39-year age bracket (Stewart et al., 2012b; see Table 1).

The breadth, reach, and scope of the conference are increasing with a notable rise in the number of locations from which participants access the event. Although numbers of those participants completing the survey from other countries remain small, we are aware from interaction with the participants through Facebook and Twitter and the written chat dialogue on the online conference that interest in Africa, Asia, and the Middle East is increasing (see Table 2).

\section{TABLE 1 Age Range}

\begin{tabular}{|cccc|}
$\begin{array}{l}\text { AGE RANGE } \\
\text { (YEARS) }\end{array}$ & $\mathbf{2 0 1 2} \boldsymbol{n}(\%)$ & $\mathbf{2 0 1 3} \boldsymbol{n}(\%)$ & TOTAL $\boldsymbol{n}(\%)$ \\
$15-19$ & $1(<1.0)$ & $2(<1.0)$ & $3(<1.0)$ \\
$20-29$ & $17(16.5)$ & $15(11.0)$ & $32(13.3)$ \\
$30-39$ & $34(33.0)$ & $39(28.6)$ & $73(30.5)$ \\
$40-49$ & $15(14.5)$ & $33(24.2)$ & $48(20.2)$ \\
$50-59$ & $24(23.3)$ & $28(20.5)$ & $52(21.7)$ \\
$60-69$ & $11(10.6)$ & $14(10.3)$ & $25(10.4)$ \\
$>70$ & $0(<1.0)$ & $1(<1.0)$ & $1(<1.0)$ \\
Missing & $1(<1.0)$ & $4(2.9)$ & $5(2.0)$ \\
Total & 103 & 136 & 239 \\
\hline
\end{tabular}

\section{Access and Technology}

There has been a growth in the number of people accessing information about the conference via the VIDM Facebook and Twitter page, which have become the main sources of promotional information. There is also a steady increase in the number of people accessing information through e-mail groups and midwifery forums, suggesting that these forums present a useful method of promoting the event internationally.

Similar to previous years, most respondents accessed the conference from home using a laptop or personal computer. There has been a notable decrease in the number of people reporting problems with using the technology. Ninety-five percent of respondents reported in the current data that they found the technology easy or very easy to use. In previous years, access to the conference was restricted by difficulties with the technology, whereas the main reasons given for not attending sessions during the live event in 2012-2013 were lack of time and working hours with no access to the event in the workplace.

\section{TABLE 2 Country of Residence}

\begin{tabular}{lcc|}
\hline COUNTRY OF RESIDENCE & $\mathbf{2 0 1 2}(\mathbf{\%})$ & $\mathbf{2 0 1 3}(\mathbf{\%})$ \\
Australia & 26.0 & 30.8 \\
Canada & 4.8 & 7.3 \\
India & $<1.0$ & 3.6 \\
New Zealand & 10.6 & 11.7 \\
United Kingdom & 18.4 & 15.5 \\
United States & 17.4 & 16.1 \\
Other & 22.8 & 15.0
\end{tabular}


Most respondents accessed more than 1 session during the live event with a range of 1-24 sessions attended. The mean number of sessions attended was five across each year, which is similar to previous years.

\section{Meeting Continuing Professional Development Needs}

When asked to describe within the free-text comments how attendance at the conference had contributed to ongoing professional development, three main themes emerged: enabling personal and professional growth, facilitating learning from others, and increased awareness of global midwifery issues (see Figure 2).

When describing why they attended the conference, the wish to connect with other midwives globally to facilitate personal and professional growth emerged as a clear theme. Respondents frequently cited their interest in particular topics or speakers and how the subject matters are presented matched their areas of interest and need for further learning. A small number of respondents mentioned that the event was cost free and accessible from home as being a major incentive to attend. Two respondents cited their interest in midwifery and future plans to join the midwifery profession as their motivation for attending:

Since this dream of mine has been a longtime coming [and I am so excited for it to finally be commencing], this sounded like a great way to satisfy some of that excitement. In summation, I cannot wait to enter into the actual midwifery course!

The development of professional knowledge was emphasized as an important contribution to CPD. For example, three respondents highlighted that access to new knowledge about one specific clinical topic "intrahepatic cholestasis in pregnancy" had been very significant for them.

Eleven respondents stated that that they felt empowered and able to make changes to their clinical practice and as a result, enhance the quality of care provided for women and their families. An example of this

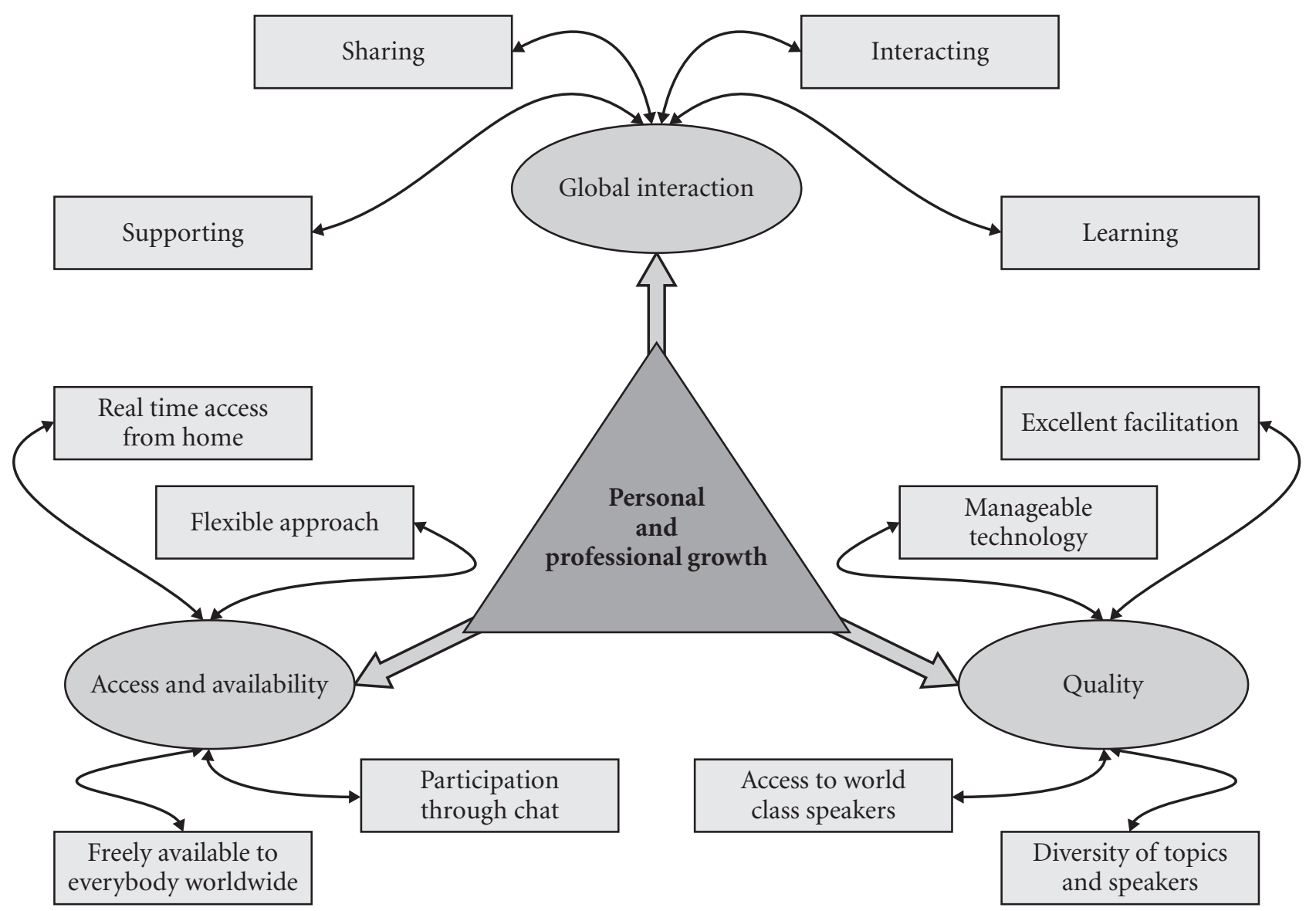

FIGURE 2 Enabling personal and professional growth. 
was from a respondent who said she would be sharing the use of social media to gain access to information and support with the women she cared for: "I enjoyed the sessions on using social media because my patients can be motivated to use it." Another described how attending the conference had enabled her to determine her future professional career direction: "My focus is changing, and the conference has helped me consolidate my thinking and increased my motivation to move forward in my newly chosen direction."

Seven respondents stated that the conference contributed to their professional development by creating feelings of "excitement" and "optimism," which "inspired" them to apply the knowledge gained to their practice: "Hearing of other people's experiences enables me to broaden my perspectives in both my personal and professional life, which have interchangeable effects on each other."

This was reflected on further by four respondents who reported feeling "motivated" to undertake further study into areas of particular interest:

It has made me want to find out more about certain topics. I am a reluctant student ... for example, the Haitian TBA program fascinates me as in Uganda, the government is trying to ban the TBAs from working... so some of the links will help me gather evidence for our local DDHS [District Director of Health Services].

\section{Learning From Others}

The ability to "interact with" and "learn from others within a global forum" was cited by 18 respondents. They particularly valued the opportunity to discuss the topics presented with the speakers and other attendees in real time because they recognized this deepened their awareness of and understanding of the topics presented:

It is so valuable to be able to learn from midwives who are speaking from around the world.

It wasn't so much about new knowledge but more about learning what others are up to outside my immediate area of practice/domain.

The synchronous nature of the conference enabled participants to interact in the chatbox with each other and the presenters, and this was appreciated by participants as articulated by this midwife from Uganda describing how the conference had assisted her professional development:

Fascinated by all the questions and answers going on in the chatbox and knowing you could ask the speaker a question directly and get answers! Opportunity to look at a wide range of subjects that you would never find together on one study day. Having people from all over the world... teaching and contributing to the discussion. Some of the side discussions were different to the topics, for example, TPA ended up in a whole discussion about the LSCS rate in India and the reasons for it.

The possibility of being able to interrelate and create connections to be built on after the conference was highlighted by five respondents: "[B]ut also the opportunity to network with others is stimulating and gives you someone else to ask."

Six respondents emphasized the access to resources such as links to relevant web pages and to the recordings of the presentations as further tools to aid ongoing professional development.

\section{Raising Awareness of Global Midwifery Issues}

An increased awareness of global midwifery issues was cited as a major contribution to CPD by more than half of all respondents: "I gained some new knowledge and ideas and was exposed to maternity issues faced by midwives from many different maternity contexts."

One midwife further noted how this had caused her to reflect on wider issues surrounding access to maternity care within a global context:

I learnt how lucky we are in Australia to have access to health/midwifery care as compared to the developing countries like Papua New Guinea and India but also how we still have much to change to improve the woman's pregnancy journey and outcome.

The contribution to the development of cultural competence and understanding was recognized from other respondents as important: "Learning different 
ways and different cultures assists me to develop a more understanding and inclusive practice when working with women from diverse countries and cultures."

A small number of respondents acknowledged an increased awareness of specific political issues in midwifery and maternity care. One respondent mentioned the importance in knowing about "the impact of the ICM standards on midwifery education and practice." Three respondents underscored the focus on human rights in births as "very valuable," and one woman said the conference had "inspired and motivated her to become more politically active" within her own country.

Some respondents further believed that by contributing to the conference, they were supporting the growth of midwifery internationally through their connection to, support of, and interaction with midwives on a global basis: "I wanted to participate to show the solidarity among women who care about women's health issues and work to improve access . . to support other midwives to raise the profile of midwives by supporting this cause."

\section{Accessibility}

The accessibility of the conference was mentioned by more than half of the respondents who believed that this facilitated their professional development. Midwives enjoyed being able to connect easily and have access to inspirational speakers from home: "[T]he opening by Frances Day-Stirk. Great to have access to such an important midwifery figure from the comfort of my own home?"

Nineteen midwives commented on the value of having the recordings of the sessions as they intended to return to these at a later date: "It is accessible while taking place, and I can now go and review the recordings of sessions I was able to attend as well as all the others! I can attend from home!"

The fact that the virtual conference exists at all and is provided freely to anyone around the world was a highlight for some: "A free presentation of this caliber is unheard of these days. For all the presenters and facilitators taking their time to give such a superb presentation, thank you all.'

\section{Quality of the Program}

Most respondents in both years commented on the overall quality of the presentations and speakers as being a major highlight of the conference. Bringing the leaders of midwifery, birthing, and women's health together within one forum was felt by many to be "amazing, brilliant, inspiring, fantastic, exciting, motivating, incredible."

The diversity of topics and the ability to discuss, debate, and learn from the world leaders in real time was a highlight for many, and several midwives commented on how this had aided their own "reflection" and prompted deeper learning.

The technology used and "professionalism" of the master facilitators and facilitators was mentioned by several participants who commented on the smooth running of the conference and the support offered to presenters:

An interesting technology to bring all midwifes together, the effort of master facilitators and facilitators was real good, interest to make perfections and keeping up timings for sessions...

\section{DISCUSSION}

It is clear that midwives, like other professionals, are restrained by commitments to work and family when seeking opportunities to engage in CPD activity. The increasing demands on professionals to remain updated have been met in large by the advancements in technology that allow for real-time communication among peers and coworkers who stay connected over the Internet (Beldarrain, 2006). The convenience and accessibility of online education continues to attract midwives who in many jurisdictions are required to demonstrate CPD to maintain their right to practice (Katsikitis et al., 2013; Nursing and Midwifery Council, 2008). The VIDM provides an ideal forum to bring like-minded people together, transcending distance and politics to create a safe welcoming space where midwives and others can share their knowledge, experience, and passion to support each other in their quest to learn and grow professionally. This coming together of likeminded people provides the potential for creating a zone of proximal development as described by (Vygotsky, 1978) within a virtual synchronous space. The VIDM enables learners internationally to close the distance between the level of actual development as determined by their own problem-solving activity to one of potential development because they have the opportunity to work collaboratively with their peers and the expert presenters. It is through this collaboration that learners are enabled to internalize new concepts (Shabani, Khatib, \& Ebadi, 2010). The synchronous nature of the 
conference clearly supports this level of peer and expert discussion and reflection around topics of interest in real time and the chat facility enables engagement and discussion to occur at all levels.

The improvements made in the support for the presenters and the participants in the use of the web conferencing technology have made a noticeable difference both to participation, global reach, and quality of the conference. The information for users is clearly and freely available on the conference wiki page and could easily provide an exemplar for others planning similar events in the future.

The use of the web conferencing technology as an open online learning environment for CPD for midwives is a relatively new phenomenon, and although this study does demonstrate an improvement in midwives digital literacy over time, the continued growth of events that enable international engagement and interaction will depend on the ability of midwives to access the conference particularly around their access to the Internet. Although it may be possible for midwives to learn asynchronously by accessing the recordings from different locations after the conference, the value of synchronous communication allowing multiple users to communicate in real time with each other and the presenter is known to enhance learning outcomes. Offir, Lev, and Bezalel (2008) demonstrated in their work comparing synchronous with asynchronous programs that it is the ability to ask high-level questions related to the material presented and discuss the material in real time with the presenter and peers that enables better understanding and deeper processing of the learned material. To provide an effective $\mathrm{CPD}$ vehicle that encourages midwives to enhance practice, increasing real-time global access will be a priority for the future development of the conference.

\section{LIMITATIONS OF THE STUDY}

This is a small study examining the responses to a survey of a proportion of attendees at an international online conference. At present, the event and evaluation is conducted in the English language, thus limiting access to those participants who do not speak English as their first language. There are plans to address this in the future and include sessions in other languages.

Although we have identified from the survey that midwives are able to use the event to develop their practice and enhance their knowledge, the information provided is limited. There is potential to examine aspects of the event in more detail to provide greater information on the value of the interactive nature of the conference and the challenges and opportunities designing and delivering an online synchronous event can create from an organization perspective. To examine the value of the synchronous nature of the event in more detail, an indepth analysis will be undertaken of the interactive features of this conference specifically the interparticipant and facilitator engagement achieved through the use of the chat facility. This topic will be the subject of a future paper and will provide other event organizers with valuable information to be used in planning similar events.

\section{CONCLUSION}

The VIDM conference is an innovative educational event that enables an increasing number of midwives and others to access high-quality professional education on an annual basis. The event has grown from a small bespoke online conference to one that now attracts the support of ICM and brings midwives together around the globe to participate in an open synchronous 24-hour educational event. The conference is freely accessible and attracts world-class speakers on an annual basis. The VIDM conference shows that when there is a will, there is a way. The technology exists to create synchronous global learning communities, and the annual VIDM event demonstrates the willingness of people to interact, discuss, and network together to share knowledge and experiences from midwifery practice and maternity care.

\section{REFERENCES}

Beldarrain, Y. (2006). Distance education trends: Integrating new technologies to foster student interaction and collaboration. Distance Education, 27(2), 139-153. http:// dx.doi.org/10.1080/01587910600789498

Brekelmans, G., Poell, R. F., \& van Wijk, K. (2013). Factors influencing continuing professional development: A Delphi study among nursing experts. European Journal of Training and Development, 37(3), 313-325. http:// dx.doi.org/10.1108/03090591311312769

Carroll, C., Booth, A., Papaioannou, D., Sutton, A., \& Wong, R. (2009). UK health-care professionals' experience of online learning techniques: A systematic review of qualitative data. Journal of Continuing Education in the Health Professions, 29(4), 235-241.

Fahy, C., \& Monaghan, J. (2005). Australian rural midwives: Perspectives on continuing professional development. Rural and Remote Health, 5, 468. Retrieved from http:// www.rrh.org.au 
Gibson, W., \& Brown, A. (2009). Working with qualitative data. London, United Kingdom: Sage.

Gould, D., Papadopoulos, I., \& Kelly, D. (2014). Tutors opinions of suitability of online learning programmes in continuing professional development for midwives. Nurse Education Today, 34, 613-618.

International Confederation of Midwives. (2011a). ICM international definition of the midwife. Retrieved from http://www.internationalmidwives.org/assets/uploads/ documents/Definition\%20of\%20the\%20Midwife $\% 20$ -\%202011.pdf

International Confederation of Midwives. (2011b). Global standards for midwifery regulation. Retrieved from http://www.internationalmidwives.org/assets/uploads/ documents/Global\%20Standards\%20Comptencies\%20 Tools/English/GLOBAL\%20STANDARDS\%20FOR\%20 MIDWIFERY\%20REGULATION\%20ENG.pdf

International Confederation of Midwives. (2013). Essential competencies for basic midwifery practice 2010. Revised 2013. Retrieved from http://www.internationalmidwives.org/ assets/uploads/documents/CoreDocuments/ICM\%20 Essential\%20Competencies\%20for\%20Basic\%20Midwifery\%20Practice\%202010,\%20revised\%202013.pdf

Katsikitis, M., McAllister, M., Sharman, R., Raith, L., FaithfullByrne, A., \& Priaulx, R. (2013). Continuing professional development in nursing in Australia: Current awareness, practice and future directions. Contemporary Nurse, 4(1), 33-45.

Koper, R., \& Tattershall, C. (2004). New directions for lifelong learning using network technologies. British Journal of Educational Technology, 35(6), 689-700.

Mayne, L. A., \& Wu, Q. (2011). Creating and measuring social presence in online graduate nursing courses. Nursing Education Perspectives, 32(2), 110-114. http://dx.doi .org/10.1007/BF03033431

Nursing and Midwifery Council. (2008). Modern supervision in action: A practical guide for midwives. London, United Kingdom: Author.

Offir, B., Lev, Y., \& Bezalel, R. (2008). Surface and deep learning processes in distance education: Synchronous versus asynchronous systems. Computers \& Education, $51,1172-1183$.

Russell, K. (2010). Midwifery conferences: What's the point? The Practising Midwife, 13(7), 40-41.

Schneider, Z., Whitehead, D., LoBiondo-Wood, G., \& Haber, J. (2013). Nursing and midwifery research: Methods and appraisal for evidence-based practice (4th ed.). Sydney, New South Wales, Australia: Elsevier.
Shabani, K., Khatib, M., \& Ebadi, S. (2010). Vygotsky's zone of proximal development: Instructional implications and teachers' professional development. English Language Teaching, 3(4), 237-248.

Siemens, G. (2004). Connectivism: A learning theory for the digital age. Retrieved from http://www.elearnspace.org/ Articles/connectivism.htm

Slowinski, J. (2000). Promoting virtual collaboration via the WWW. TechKnowLogia, 2(5), 44-45. Retrieved from http://www.techknowlogia.org/TKL_active_pages2/ CurrentArticles $/$ main.asp? IssueNumber=7\&FileType $=$ HTML\&ArticleID $=178$

Stewart, S., Sidebotham, M., \& Davis, D. (2012a). International networking: Connecting midwives through social media. International Nursing Review, 59(3), 431-434.

Stewart, S., Sidebotham, M., \& Davis, D. (2012b). The virtual international day of the midwife: Social networking for continuing professional development. Nurse Education in Practice, 12(5), 248-252.

Vilain, A. D., \& Stewart, S. (2012). The end of an era? Midwifery conferences. The Practising Midwife, 15(11), 20, 22-23.

Vygotsky, L. (1978). Mind in society: The development of higher psychological processes. Cambridge, MA: Harvard University Press.

Correspondence regarding this article should be directed to Mary Sidebotham, PhD, Griffith University, Logan Campus, School of Nursing and Midwifery, Academic Drive, Meadowbrook, Queensland 4131, Australia. E-mail: m.sidebotham@ griffith.edu.au

Mary Sidebotham, PhD, RM, associate professor and director, Primary Maternity Care Programs, School of Nursing and Midwifery, Logan Campus, Griffith University, Meadowbrook, Queensland, Australia.

Annette Dalsgaard, MEd, Master of ICT and Learning, RM, $\mathrm{PhD}$ student, research assistant, senior lecturer, ResearchLab for ICT and Learning Design, Philosophy and Learning, Faculty of Humanities, Aalborg University, Copenhagen SV, Denmark.

Deborah Davis, PhD, RM, professor of midwifery, Clinical Chair, ACT Health Directorate and University of Canberra, Faculty of Health, University of Canberra, ACT, Australia.

Sarah Stewart, Msc, RM, social media and e-learning consultant, Canberra, ACT, Australia. 